\title{
The aging gut microbiome and its impact on host immunity
}

\author{
Nabil Bosco $\mathbb{D}^{1} \cdot$ Mario Noti $\mathbb{D}^{2}$
}

Received: 7 January 2021 / Revised: 11 March 2021 / Accepted: 25 March 2021 / Published online: 19 April 2021

(c) The Author(s), under exclusive licence to Springer Nature Limited 2021

\begin{abstract}
The microbiome plays a fundamental role in the maturation, function, and regulation of the host-immune system from birth to old age. In return, the immune system has co-evolved a mutualistic relationship with trillions of beneficial microbes residing our bodies while mounting efficient responses to fight invading pathogens. As we age, both the immune system and the gut microbiome undergo significant changes in composition and function that correlate with increased susceptibility to infectious diseases and reduced vaccination responses. Emerging studies suggest that targeting age-related dysbiosis can improve health- and lifespan, in part through reducing systemic low-grade inflammation and immunosenescence-two hallmarks of the aging process. However-a cause and effect relationship of age-related dysbiosis and associated functional declines in immune cell functioning have yet to be demonstrated in clinical settings. This review aims to (i) give an overview on hallmarks of the aging immune system and gut microbiome, (ii) discuss the impact of age-related changes in the gut commensal community structure (introduced as microb-aging) on host-immune fitness and health, and (iii) summarize prebiotic- and probiotic clinical intervention trials aiming to reinforce age-related declines in immune cell functioning through microbiome modulation or rejuvenation.
\end{abstract}

\section{Introduction}

Age-related declines in the immune system significantly affect the health and well-being of the elderly [1]. Such loss of power of the immune system, termed immunosenescence, correlates with decreased vaccination responses and increased incidence and severity of infectious disease [2]. This is once more exemplified by the current COVID19 pandemic, where age and frailty are among the strongest predictors for morbidity and mortality to SARS-CoV-2 infection $[3,4]$. Aging does not only impair proper immune cell functioning, but virtually affects all tissues and cellular circuits in our bodies resulting in frailty and death. Even the

Nabil Bosco

nabil.bosco@rd.nestle.com

$\triangle$ Mario Noti

mario.noti@rd.nestle.com

1 Nestlé Research, Nestlé Institute of Health Sciences, Department of Cell Biology, Cellular Metabolism, EPFL Innovation Park, Nestlé SA, Lausanne, Switzerland

2 Nestlé Research, Nestlé Institute of Health Sciences, Department of Gastrointestinal Health, Immunology, Vers-Chez-les-Blancs, Nestlé SA, Lausanne, Switzerland trillions of microbes that host our bodies are not exempt from aging and its consequences. While the microbiota is relatively stable throughout adulthood, aging induces significant shifts in gut microbiome composition and function associated with a decline in diversity [5]. Given the intimate involvement of the gut microbiome in proper functioning of the host-immune system [6-8], targeting age-related dysbiosis may represent an attractive strategy to prevent or restore functional declines in immune responses as we age. This may occur indirectly through sustaining intestinal tissue function and regeneration thus reducing microbial extravasation, uncontrolled activation of immune cells and inflammaging or through direct effects on the hematopoietic stem cell niche or hematopoiesis itself. With a central role of the gut microbiome on the immune system, future vaccine successes and strategies to reinforce the aging immune system critically depend on a better understanding of the aging host-microbe superorganism.

\section{General hallmarks of immune aging}

\section{Immunosenescence}

While aging mainly refers to chronological aging (time), each individual ages biologically with a different pace 
reflecting individual cumulative erosion of the various tissues, organs, or systems [9]. Biological age is influenced by each individual's genetics, environment, and lifestyle $[10,11]$. The term "immunosenescence" was introduced few decades ago to refer to functional impairments, faulty or aberrant immune responses observed in elderly [1]. Agerelated changes in the quality and quantity of immune responses lead to a progressive decline in the ability to trigger effective antibody and cellular responses against infections and vaccinations [2,12]. This is exemplified by epidemiological studies associating elderly (often defined as people older than 65 years) with higher risk for infections, autoimmune disorders, malignancies and mortality [13, 14]. Cellular and molecular features of immunosenescence were described for both the innate and adaptive immune system $[15,16]$. T-lymphocyte biology of aging was prominently studied, but all hematopoietic-derived cells show hallmarks of aging including the presence of dysfunctional antibodyproducing $\mathrm{B}$ cells, antigen-presenting cells, natural killer cells, and neutrophils [2-5]. Epigenetic alterations were also reported in the earliest hematopoietic progenitors that may explain observed age-related myeloid skewing [17]. Despite the biology of immune aging is an intensively studied topic and strategies to remove senescent cells from our bodies using senolytics are emerging, there is still no consensus on the triggers of senescence. Aging of primary lymphoid organs (bone marrow and thymus attrition), chronic antigenic overload (e.g., CMV), gut dysbiosis or inflammation are proposed drivers of immunosenescence that together with an accumulation of genetic defects, cellular stress, and/ or cell exhaustion cause a drop in immune fitness as we age [18-21].

\section{Inflammaging}

Inflammation is a highly controlled physiological process critical to fight pathogens, mop up debris and heal injuries [22]. As we age, the dynamic balance of pro- and antiinflammatory networks declines as a result of a complex and changing interplay of genetic, environmental, and lifestyle factors [23, 24]. This non-resolving, chronic inflammatory state-termed inflammaging-represents a significant risk factor for both morbidity and mortality [25]. Several factors including chronic infections, physical inactivity, visceral obesity, diet, psychological stress, sleep deprivation, or intestinal dysbiosis can initiate and maintain inflammaging [26]. Chronic exposure to stressors promotes cell senescence and dysregulation of innate immunity-a major characteristic of inflammaging - that mirrors in consistently elevated local and systemic levels of inflammatory mediators with interleukin-6 (IL-6), tumor necrosis factor- $\alpha$ (TNF $\alpha$ ), IL- $1 \beta$, and C-reactive protein (CRP) commonly reported in aged individuals [27]. Although dysregulation of an innate monocyte-macrophage network may be at the center of inflammaging [28, 29], emerging evidence suggest a critical role for senescent cells including $\mathrm{T}$ and $\mathrm{B}$ cells that through their senescent-associated secretory phenotype contribute to chronic low-grade inflammation [30]. In return, chronic expression of or exposure to inflammatory stimuli may render pre-activated immune cells refractory to further stimulation leading to the observed increased frequency and severity of infectious diseases in the elderly. Thus, preexisting inflammation has been demonstrated to be an important determinant of vaccine responsiveness [31, 32]. Indeed, chronic low-grade inflammation has a negative impact on host immunity, as elevated inflammatory responses are detrimental for vaccine efficacy against influenza [33] or yellow fever [34]. In this context, clinically approved drugs with immunomodulatory properties such as metformin, imiquimod [35] and anti-inflammatory drugs (e.g., aspirin and NSAIDS) may represent attractive approaches to increase efficacy of vaccines by transiently alleviating chronic low-grade inflammation prior to vaccination $[36,37]$. Further, inflammaging may have multiple health consequences by fueling age-associated diseases including metabolic syndrome, cardiovascular disease, sarcopenia, cancer, and neurodegenerative diseases as most if not all age-related disorders share an inflammatory signature. Despite communalities between aging, inflammation, and chronic disease, biomedical research continues to spend billions of dollars to tackle each of these disease states individually [38]. This raises the provocative question whether targeting chronic low-grade inflammation or the mechanisms causing inflammaging may slow down aging and its associated diseases.

While preclinical studies suggest inflammation as a causative factor of age-related disease and reduced immune responsiveness [39, 40], human data confirming this hypothesis is largely missing. However, a recent study generated by The Canakinumab Anti-inflammatory Thrombosis Outcome Study holds big promise for gerosciences. Treatment of more than 10,000 stable patients with previous myocardial infarction with Canakinumab (a human monoclonal antibody targeting interleukin-1 $\beta$ ) significantly reduced systemic low-grade inflammation in study participants [41, 42]. Importantly, treatment regimens prevented recurrent vascular events as well as incidence of lung cancer [43]. While such studies evoke hope for efficacious anti-aging therapies, reducing systemic inflammation through targeted blockade of key inflammatory mediators needs to be carefully balanced with regard to susceptibility to infectious disease [42].

More recently, the importance of inflammation in aging associated complications lead to the development of a variety of immune metrics claiming to predict morbidity and mortality. Such immune metrics include iAGE based on 
an inflammatory age score [44], GlycanAge relying on immunoglobulins glycation [45] or Nightingale health index where systemic inflammation with glycoprotein acetylation (GlycA) predicts long-term risk of respiratory infections, cardiovascular diseases and all-cause mortality [46]. With health management in aging societies becoming a growing economic burden, such immune metrics represent promising tools to identify at risk individuals for early pharmacological or nutritional intervention [47].

\section{Aging and the gut microbiome-growing old with our intimate friends}

Similar to host-cellular systems, the gut microbiome undergoes dynamic changes through time as it integrates and responds to signals from the environment [48, 49]. Diet, drug use, physical activity, and social environment are among the factors that constantly shape the composition and function of the gut microbiome [50]. An imbalance in the microbial community structure-referred to as dysbiosisis a common accomplice of age-related disorders that collectively represent the leading cause of disability and mortality worldwide [51]. To cope with a constant changing environment, the gut microbiome responds in a dynamic manner both through changes in bacterial species composition and metabolic function. This process is tightly regulated by the host-immune system that figures as an architect to shape the gut microbiome by allowing commensal bacteria to thrive and occupy mucosal niches while selectively eliminating or neutralizing harmful microbes. As immune fitness progressively declines with age, surveillance of this dynamic host-microbial handshake is impaired resulting in wide-ranging functional consequences for host health and immunity (Fig. 1).

In humans, age-related dysbiosis-here introduced as microb-aging - is characterized by a loss in Clostridiales and Bifidobacterium, with an enrichment in Proteobacteria and an overrepresentation of pathobionts such as Enterobacteriaceae $[48,52,53]$. The current knowledge of agerelated changes in gut microbiota composition, function and diversity has been comprehensively reviewed elsewhere [54-58]. Environmental factors, diet or medication have a profound impact on gut microbiome composition and function [59, 60]. However, the assembly of gutmicrobial community structures may also be dictated by host organ function. Given the intestine is subject to significant age-related changes in tissue function and integrity such as alterations in regenerative capacity, epithelial barrier formation, mucus layer composition, and peristalsis [61-63], it is likely that changes in the mucosal niche contribute to dysbiotic states as we age [64]. Such subclinical changes in intestinal integrity may promote microbial extravasation to systemic sites, systemic low-

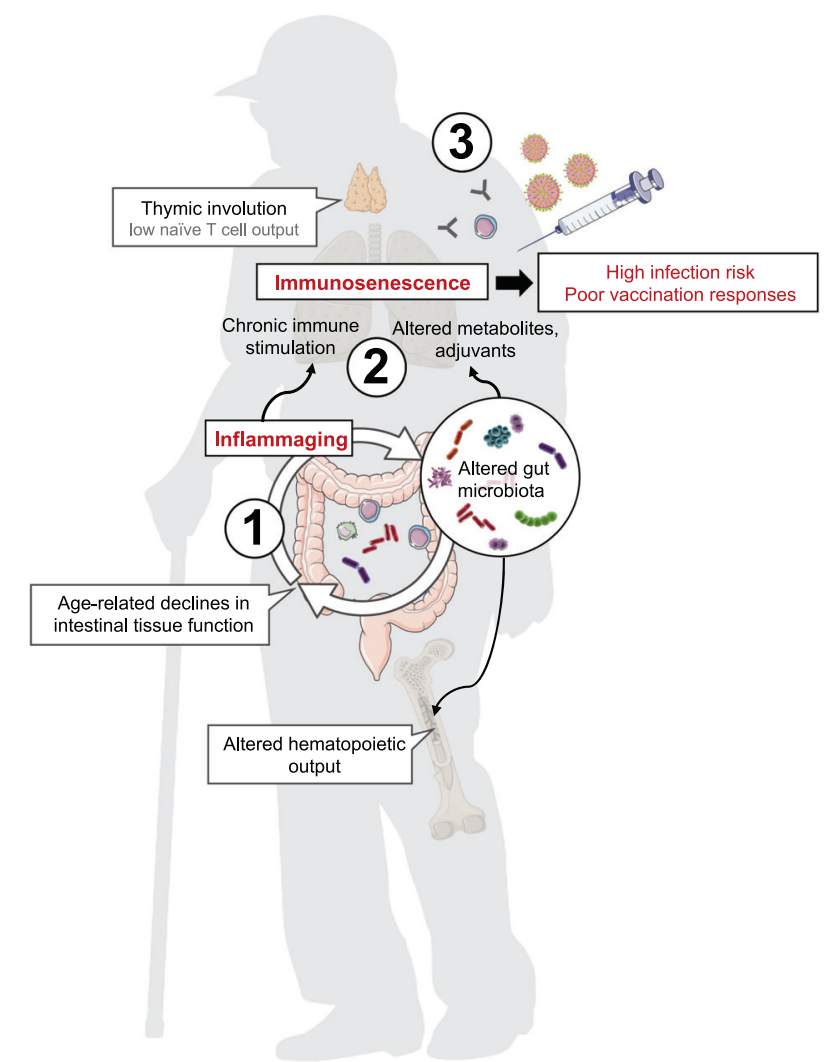

Fig. 1 Microb-aging and related consequences for host immunity -a hypothetical model. Age-related changes in gut-microbial communities and associated declines in intestinal tissue function may fuel inflammaging, creating a vicious cycle further impacting hostmicrobiome interactions (1). Chronic immune stimulation as a consequence of systemic low-grade inflammation and changes in the metabolome and microbial stimuli contribute to immunosenescence (2) that together with impaired immune repopulation (e.g., thymic involution, altered hematopoiesis) result in increased infection risk, and poor vaccination responses in the elderly (3).

grade inflammation, onset of chronic inflammatory disease, and premature mortality. However, identifying causal relationships in humans remain challenging and are discussed below.

Although we are starting to understand how bacterial taxonomic composition and diversity change in response to age, our knowledge on bacterial evolution and associated functional consequences for host fitness remains enigmatic. Two scenarios are possible: (i) observed age-related changes in gut-microbial community structures are a simple consequence of physiological tissue adaptations occurring during host aging or (ii) age-related dysbiosis is a product of bacterial evolution that directly triggers host aging by enabling specific bacterial taxa to escape immune surveillance. A better knowledge of the aging host-microbial superorganism is thus of utmost importance to forge ahead microbiome-based therapies to fight aging and age-related diseases. 


\section{Microb-aging - driver of immunosenescence and frailty?}

Age-related alterations in the composition of the intestinal microbiota not only occur in humans but also laboratory model organisms - from flies to fish to mice. These model systems that control for genetics, age, diet, and the microbiome itself provide strong scientific evidence that intrinsic alterations in host physiology or microbial evolution are sufficient to promote a dysbiotic state [65, 66]. Importantly, these model organisms have demonstrated that the gut microbiome has the potential to beneficially modulate aging processes to promote health- and lifespan of the host. Studies with the fruit fly Drosophila melanogaster - a frequently used aging model to study the interplay between microbial dynamics, age-related changes in intestinal physiology and organismal health-have elegantly demonstrated that intestinal dysbiosis not only precedes, but also predicts the onset of age-related intestinal barrier dysfunction, systemic immune activation, and organismal death [67]. In line, flies maintained under axenic conditions throughout life displayed reduced rates of aging [68] suggesting that preventing age-associated dysbiosis in these model settings can limit inflammaging and improve immune homeostasis to promote organismal health [69].

Using the African turquoise killifish (Nothobranchius furzeri), a naturally short-lived vertebrate, Smith et al. further substantiate the impact of the gut microbiota in modulating aging processes. Heterochronic colonization of middle-aged fish with the microbiome of young donors induced long-lasting beneficial systemic effects that led to vertebrate lifespan extension. Colonization of aged fish with a young donor microbiome associated with the presence of key bacterial genera known to produce metabolites both capable of maintaining immune system health and having anti-inflammatory effects [70].

Similar to studies in fish, fecal microbiota transplantation from young donors into progeroid mice improved healthand lifespan of the latter with transfer of the verrucomicrobia Akkermansia muciniphila being sufficient to exert the observed beneficial effects [71]. Further, an age-related loss of Akkermansia muciniphila has been associated with impaired intestinal integrity and insulin resistance-a process that is mediated through a microbiome-monocyte- $\mathrm{B}$ cell axis [72]. Apart from its effects on host metabolism, Akkermansia muciniphila has also been implicated in regulating antigen-specific T-cell responses and antibody production to modulate host-immune function [73].

Using an alternative approach, Fransen et al. colonized germ-free (GF) mice with either the gut microbiome of young or old mice. Transfer of an aged donor microbiome to young mice was sufficient to promote intestinal inflammation, leakage of microbial products to the circulation, and the onset of chronic-low-grade inflammation. As a consequence of systemic low-grade inflammation, increased Tcell activation in systemic immune compartments was observed [74]. Another seminal study reports similar findings with transplantation of an aged microbiome to promote systemic low-grade inflammation in young GF recipients. Inflammaging in these settings was further associated with dysregulated macrophage function that manifested in poor bacterial killing activity with macrophages representing a potent source of inflammatory cytokines. Further, genetic or antibody mediated depletion of TNF $\alpha$, a signature cytokine of low-grade inflammation, prevented age-related gut dysbiosis, and associated systemic low-grade inflammation [75].

A more recent study by Donaldson et al. highlights that age-related declines in intestinal immunity can be restored by boosting M-cell numbers through manipulation of the gut microbiome [76]. Both exposure of aged mice to a young microbiome or stimulation with flagellin were sufficient to observe this effect with restoration of M-cell maturation in Peyer's patches, enhanced antigen uptake, and increased intestinal IgA responses in aged mice. M-cell restoration in response to microbiome-based interventions did rely on improved intestinal stem cell function suggesting that restoration of the regenerative capacity of the aged intestine may have the added benefit to improve intestinal immunity. These findings might be of relevance to improve oral vaccination responses or prevent gastrointestinal infections in the elderly.

Besides local immune regulation, age-related changes in the gut commensal community structure may also have direct effects on hematopoiesis. Studies in mice have demonstrated that alterations in the gut microbiome associate with multilineage alterations in hematopoiesis with suppression of multipotent progenitors [77]. Given that the gut microbiome is intimately involved in the control of bacterial infections by promoting hematopoiesis, agerelated changes in the balance and diversity of the gut microbiota may lead to impaired hematopoiesis, higher susceptibility to infections and reduced vaccination responses in the elderly [78, 79]. However, additional studies are required to support this hypothesis aiming for a better understanding of the effects of age-related dysbiosis on the regulation of the hematopoietic system.

Collectively, these findings in preclinical model systems demonstrate that correction of age-associated intestinal dysbiosis is beneficial and thus provide a rationale for microbiome-based therapeutic approaches to improve immune system functioning, fight aging, and its associated disorders. While fecal microbiota transplants (FMT) have antiaging properties in animal models (see above) and FMT has been successfully used to treat recurrent Clostridium difficile infection in men, several barriers remain to propose FMT as anti-aging strategy in clinical settings. A better 
understanding of the characteristics of a healthy microbiome is of utmost importance (including virome and fungome) to ensure the safety of the recipient with respect to long-term outcomes.

\section{Impact of the gut microbiome on vaccine responses}

Despite unprecedented advances in our understanding of the gut microbiome across life, its potential on vaccinology has yet to be realized. Given that the microbiome tightly regulates immune cell development and function [80-82], it may ultimately affect vaccine efficacy [83-85]. Variation in gut-microbial community structures due to environmental, socioeconomic, nutritional, or hygiene conditions may thus explain observed geographical heterogeneity in vaccine responses $[50,86]$. Therefore, a better mechanistic understanding on how the microbiome may boost vaccination responses may help to develop new strategies to curtail infectious death in the elderly.

Until recently, the best evidence suggesting that the gut microbiome affects vaccination responses comes from preclinical model systems using axenic or microbiota-depleted mice. Woo et al. explored the effects of different antibiotic regimen on the antigen-specific humoral immune responses [87]. Clarithromycin, doxycycline, and ampicillin effects on the primary and secondary antibody responses to tetanus toxoid (TT), a pneumococcal polysaccharide vaccine (PPV), a hepatitis B virus surface antigen (HBsAg) vaccine, and live attenuated Salmonella typhi (Ty21a) were investigated in mice. Interestingly, both antigen and antibiotic specific responses were affected. While clarithromycin and doxycycline, suppressed typical T-cell-dependent and Tcell-independent antibody responses, poor or no effect was observed with ampicillin. Additionally, all three antibiotics and particularly ampicillin enhanced the humoral response to Ty21a-a live attenuated bacterial mucosal vaccine model. Further work involving vaccination experiments in GF mice confirmed these initial findings as recently reviewed $[49,88]$. So far existing work focused on bacteria, and other constituents of the microbiota including viruses, fungi, protozoa and archaea are less studied. Yet, two important questions remain: (i) What are the mechanisms by which the microbiota participates to host-immune responses (particularly vaccine response) and (ii) what are the human implications of such findings?

To date, the most convincing data demonstrated that gut microbiota provides a natural source of adjuvants capable of modulating host systemic and mucosal vaccine responses. This was first proposed after the system biology report of Nakaya et al. who described an early (day 3) and transient gene upregulation of toll-like receptor-5 (TLR5) in human after non-adjuvanted influenza vaccination with trivalent inactivated vaccine (TIV) [89]. TLR5 expression positively correlated with magnitude of the hemagglutination inhibition (HAI) titers induced by TIV across several vaccination seasons. Subsequently, the same group demonstrated that TLR5 sensing of flagellin secreted by mouse gut microbiota was implicated in the TIV-mediated response [90]. While direct flagellin administration or flagellated bacteria transplant can provide natural adjuvant to improve non-adjuvanted influenza vaccine response, it did not with other adjuvanted or live vaccines such as Tetanus-Diphtheria-Pertussis (Tdap), yellow fever (YF-17D), or recombinant hepatitis B antigens (Recombivax HB). Next to TLR5, the specific contribution of a second pattern recognition receptor called nucleotidebinding oligomerization domain 2 (NOD2) was described in a mouse model of mucosal vaccine responses induced by intranasal challenge with human serum albumin (HSA) antigens and cholera toxin (CTX) adjuvant [91]. In GF mice, antibiotic-treated mice or mutants genetically modified to lack NOD2 signaling, HSA-specific IgG responses were consistently reduced. When those animals received muramyl dipeptide (MDP), a peptidoglycan recognized by NOD2, or MDP expressing bacteria, HSA-specific IgG responses were restored. While human relevant vaccines were not used yet, this second piece of work suggests that resident microbes could also enhance adjuvant effect of CTX used in mucosal vaccination protocols. Further work is necessary to reveal the immunological capacity of the gut microbiome, its cell wall components or metabolites to act as endogenous vaccine adjuvants to amplify adaptive immune responses to specific pathogens.

In the same line, both preclinical and clinical reports observed a positive impact of dietary fiber on functional immune parameters including vaccination responses [88, 92-100] (see Table 1), further supporting an important immunomodulatory potential of the gut microbiota based on its composition (nature of bacteria) and or activity (nature of metabolites secreted). This is exemplified by the large literature existing on immunomodulatory activity of short chain fatty acids (SCFAs) resulting from fiber digestion. Those metabolites are released locally or systemically participating to general host physiology as extensively reviewed by others [101-104].

Dynamics in gut microbiome composition and function may also explain observed geographical heterogeneity in vaccine responses. We and others also reported significant differences in the magnitude of the humoral immune responses after influenza vaccine in adults or elderly (more than 100-fold [105-107]). Similarly, children from developing countries responded far less to a variety of vaccines than children from industrialized countries as exemplified by studies from the tuberculosis protection program with Bacillus Calmette-Guerin (BCG) vaccine studies across countries with protection range spreading between 0 and $80 \%$ [108]. Host genetics, nutritional status, breastfeeding 


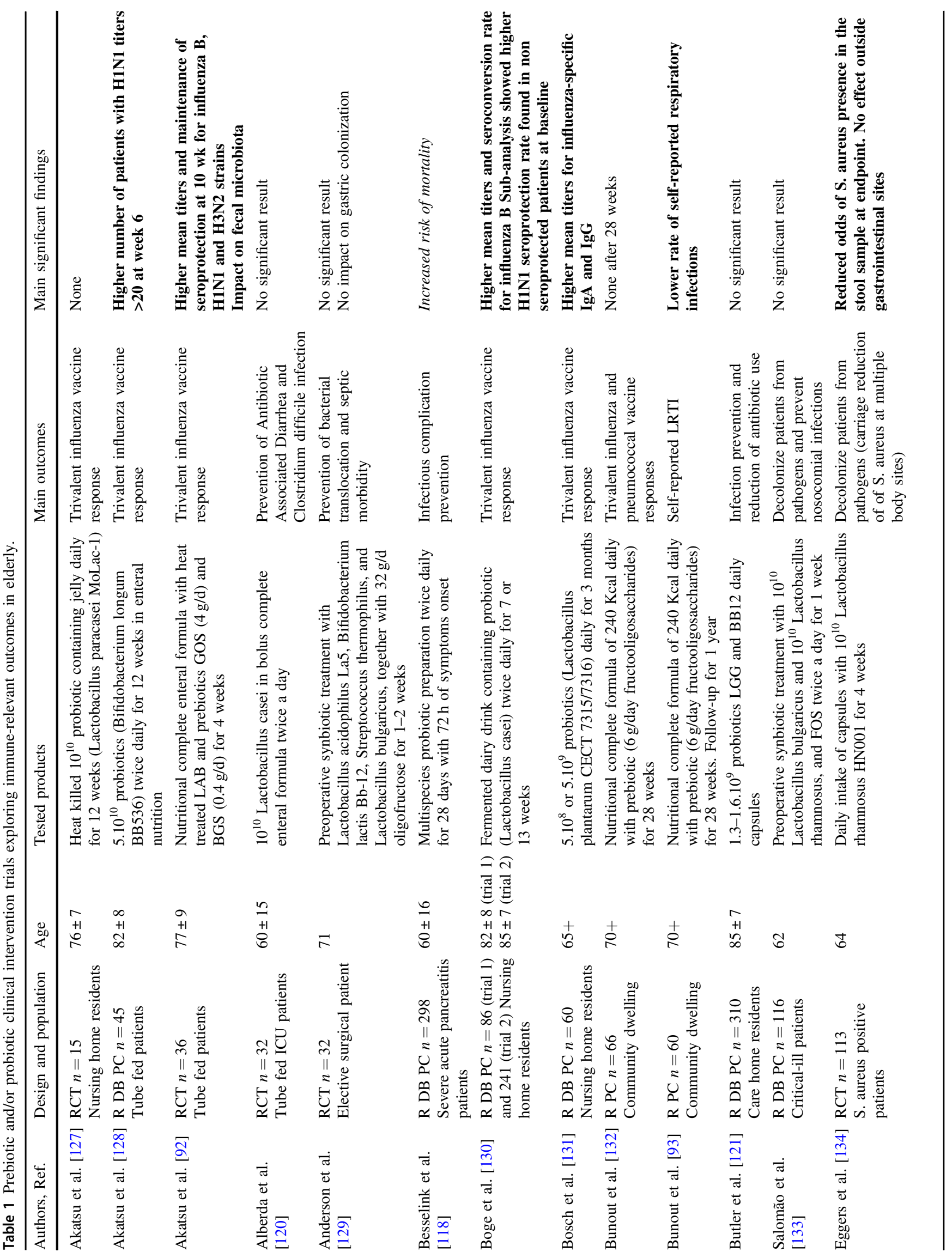




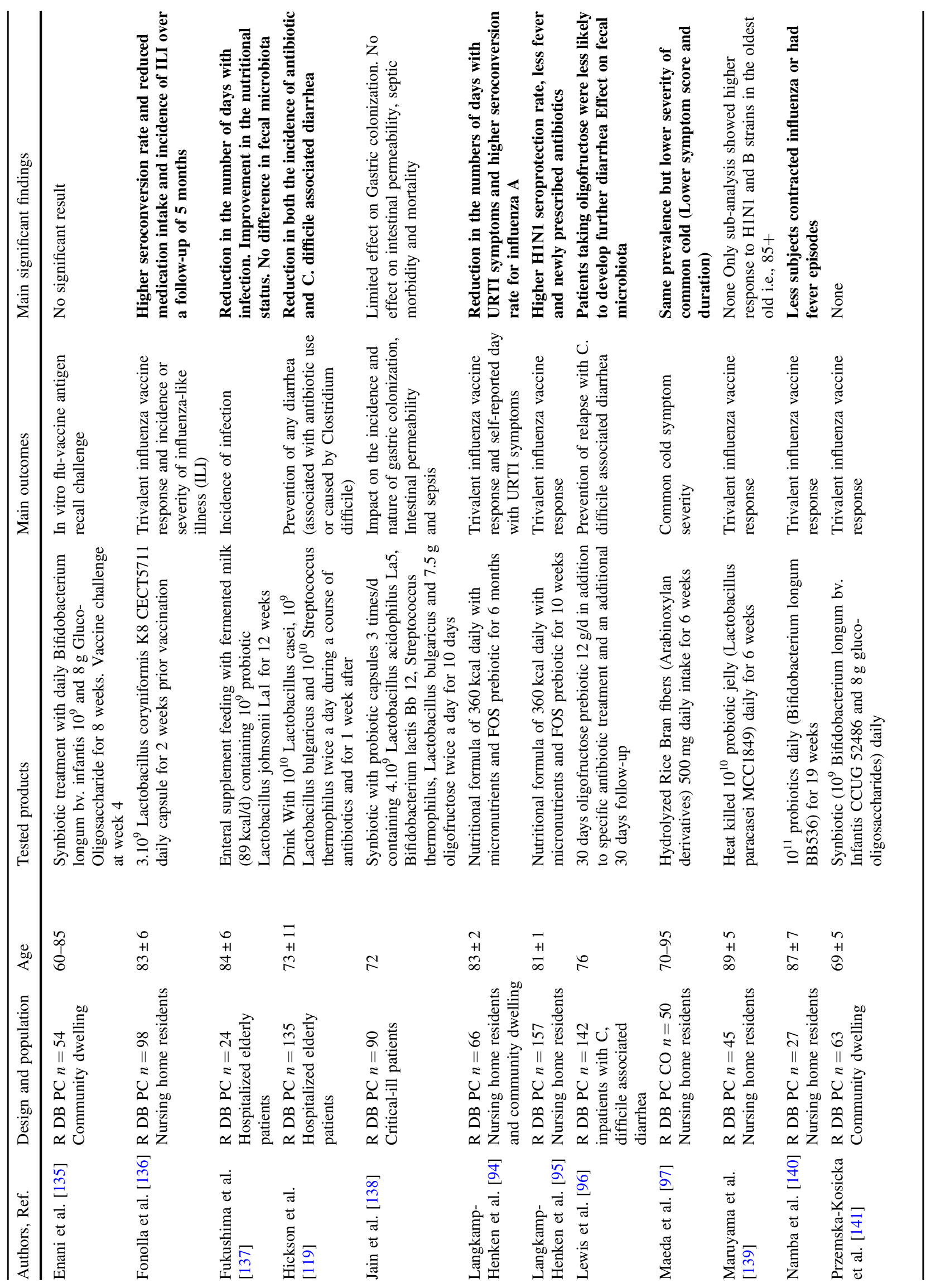




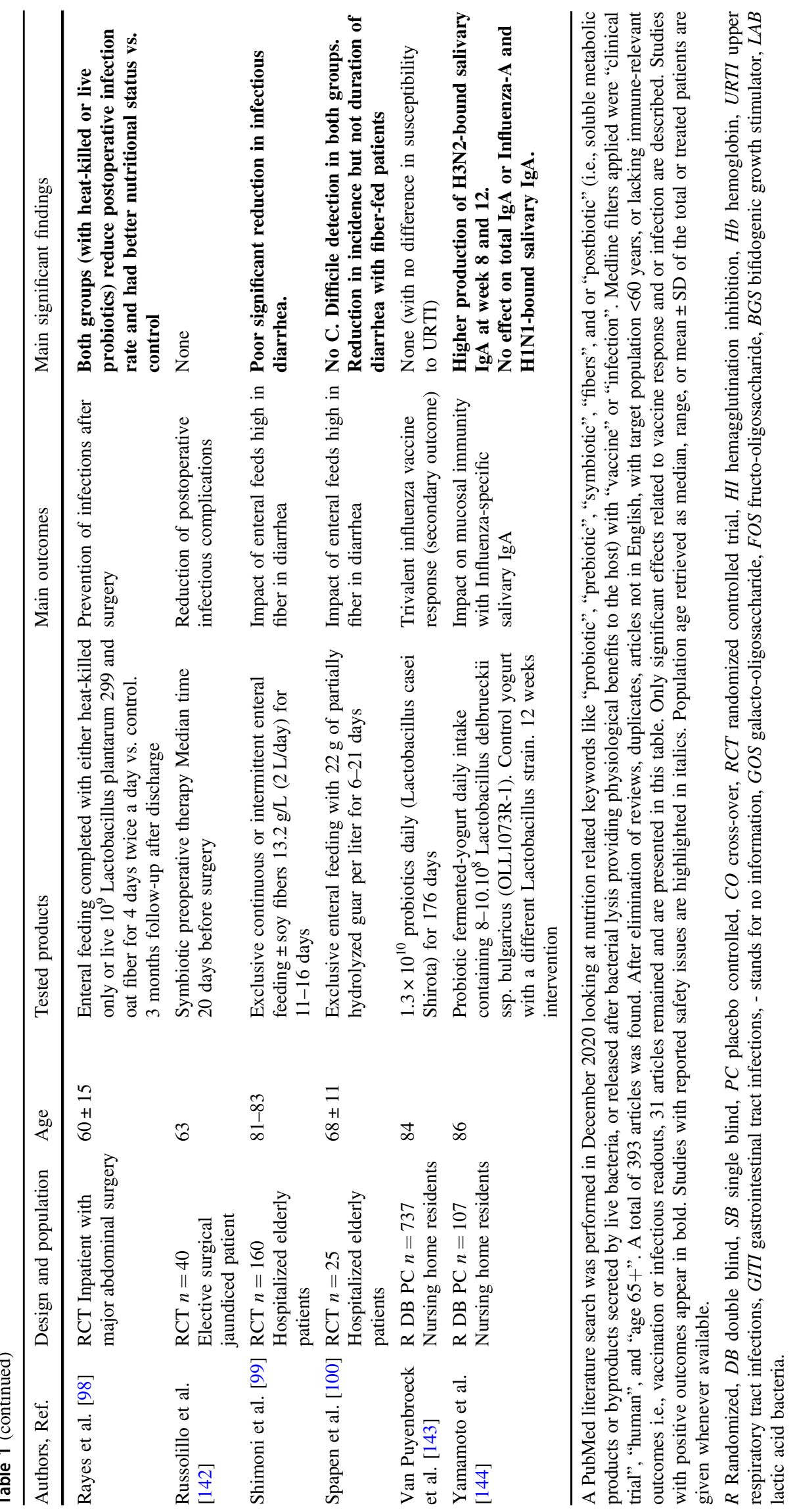


practices as well as sanitation and or prior exposure to the pathogens, were proposed to explain variation in vaccine immunogenicity. However, recent technological improvements to study host microbiota shed new light in this field. Indeed, studies on stool microbiota characterization suggest that gut-microbial species composition may influence vaccination efficacy in the context of oral polio, BCG, TT, and HBV [109].

In addition, high prevalence of small intestinal bacterial overgrowth (SIBO) is often observed in children from developing countries. SIBO could also limit vaccine performance due to associated malabsorption, competition between gut microbiota and host-immune cells for key nutrients and or systemic release of microbial molecules through a leaky gut [110]. Indeed, hyporesponsive whole blood cells (with standard TLR stimulation assays) were observed in samples collected from children living in the poorest regions (South Africa) compared to age-matched samples from children living in wealthier regions (North America and Europe) [111, 112].

The above human studies were only correlative. Three studies were carried out recently to establish causality between gut microbiota dysbiosis and vaccine response in infants and adults. In the first large $(n=754)$ and well controlled study, broad-spectrum antibiotic treatment (azithromycin) reduced prevalence of pathogenic intestinal bacteria, while it did not improve oral polio vaccination in Indian infants [113]. Next, Harris et al. treated 66 Dutch healthy adults in an open-label trial with both narrowspectrum antibiotic (vancomycin) or broad-spectrum antibiotics (vancomycin, ciprofloxacin and metronidazole) and studied responses of TT, oral rotavirus (RV), and polysaccharide pneumococcal (Pneumo23) vaccines [114]. While some positive effects were observed with RV vaccine, the antibiotic treatments did not improve TT or Pneumo23 responses. Lastly, Hagan and colleagues carried out an elegant study with 22 young adults treated with broad-spectrum antibiotics (vancomycin, neomycin and metronidazole) followed by TIV challenge [115]. While such treatment had limited impact in adults previously vaccinated against influenza, a second trial among 11 healthy individuals who had no prior exposure to influenza (vaccination or natural infection) provided breakthrough findings. Those naïve antibiotictreated individuals had greatly impaired humoral immune responses particularly against H1N1 influenza strain. These data confirmed earlier mouse studies [90] and demonstrate that antibiotic-driven dysbiosis lead to significant alterations of vaccine responses elicited by non-adjuvanted TIV. A deeper molecular profile with system biology methodology also revealed a specific inflammatory gene signature with more activated myeloid dendritic cells associated to antibiotic treatment and reminiscent to what was already described in elderly individuals.
Going forward, rationally designed vaccines leveraging the microbiome as endogenous adjuvant holds promise in the field of vaccinology. Such approaches may require personalization and engineered reversibility to manage efficacy and potential complications in frail individuals [116]. Given that diet is one of the most potent factors shaping the gut microbiome, nutritional interventions with pre- and probiotics that promote a diverse microbiome to sustain health have received considerable interest as discussed below.

\section{Nutritional strategies to fight age-related declines in host immunity}

The concept of food developed to promote health or reduce the risk of disease was introduced in the mid-1980s in Japan by health authorities under the term "functional foods" [117]. Health authorities wanted to support preventive nutrition-based approaches to improve quality of life and reduce health care cost associated to an ageing population [117]. As a result of the intimate interaction of the gut microbiome with the host-immune system, functional foods studied in clinical trials to improve elderly immunity comprise mainly prebiotics (e.g., fibers), probiotics, a combination of both (i.e., symbiotics), or secreted soluble metabolites (also called postbiotic e.g., SCFA). As immune fitness declines with age that associates with the inability of older adults to fight infections and respond to antigenic challenges [13], most of these trials explored infection prevalence severity and duration or specific vaccination outcomes. Among the 400 clinical studies identified, we retained 31 studies based on their relevance (immune readouts and target population being elderly individuals $>60$ years) and summarized them in Table 1. Those studies were conducted in community-dwelling individuals, nursing home residents or hospitalized patients who can take oral supplement or need tube-feeding. The majority of the studies identified (20 studies) were Randomized Double Blind Placebo controlled with well-balanced groups to take into consideration classical confounding factors like age, gender and sometimes medical conditions, nutritional status and history of infection or immunization. Except one study with severely ill pancreatitis patients, where probiotic intake had severe adverse events [118] (highlighted in red in Table 1), all the nutritional interventions were reported to be safe. About two third of the studies (19 out of 31) had positive outcomes (highlighted in green in Table 1), with either improved vaccine responsiveness and or reduction of infection (severity or prevalence). However, we cannot exclude potential publication bias with positive results. Most of the studies used probiotics (live or heat killed) alone or in combination with prebiotics (symbiotic). It explored mainly the impact of the nutritional formulation on 
TIV response (seasonal vaccine) or influenza-specific antigen recall response in vitro (14 studies). Half of them had positive outcomes with expected improved seroconversion, and or reduced upper-, and lower respiratory tract infection episodes or reduced influenza-like illness (numbers, severity, and or duration). Interventions conducted by academics and the food industry to improve immune system functionality commonly used influenza vaccine challenge models. This bias can be explained by its public health relevance as well as the existing link between antibody titers following vaccination and protection against respiratory infections. It is linked to established seroconversion and seroprotection titers accepted by regulatory bodies to claim improvement of immune function.

Protection against infectious complications and particularly Clostridium difficile associated diarrhea in critical ill or elective surgical patients represented a second field of interest $[96,100,119,120]$. In the 13 studies conducted in an elderly population, 6 were positive. Their positive nature may also suggest that disease prevention may be achieved by different aspects of human immune system. Vaccine challenge studies routinely test the function of the adaptive immune system while not addressing consequences of an age-related decline of innate immunity in some bacterial infections. However, in the largest study conducted in 23 care homes in the United Kingdom and recently reported as the Probiotics to Reduce Infections iN CarE home reSidentS trial, LGG, and BB12 daily capsule intake for up to 1 year had no effect on the prevention of infection [121]. No difference was found regarding signs of infection, antibiotic use, hospitalization, or mortality.

Overall, there is a lack of consistency between studies which may have multiple reasons such as strain specific differences or doses, as well as prebiotic nature and quantity, or age and medical conditions of the subjects. Of note, none of these studies identified did an extensive analysis of the patient microbiota pre- and postintervention. While those data may exist as independent reports to characterize the ingredient properties, it would be crucial in the future to conduct systematic parallel evaluation of human microbiota and immune parameters preand post-intervention to reveal relevant interactions or causalities as exemplified by the seminal work of Hagan and colleagues discussed earlier [115].

\section{Conclusions and future perspectives}

In the past 12 months, we were painfully reminded how age affects our immune fitness resulting in increased susceptibility to fatal infectious disease. Although chronological age is nonreversible, aging associated alterations in the gut microbiome, inflammaging, and

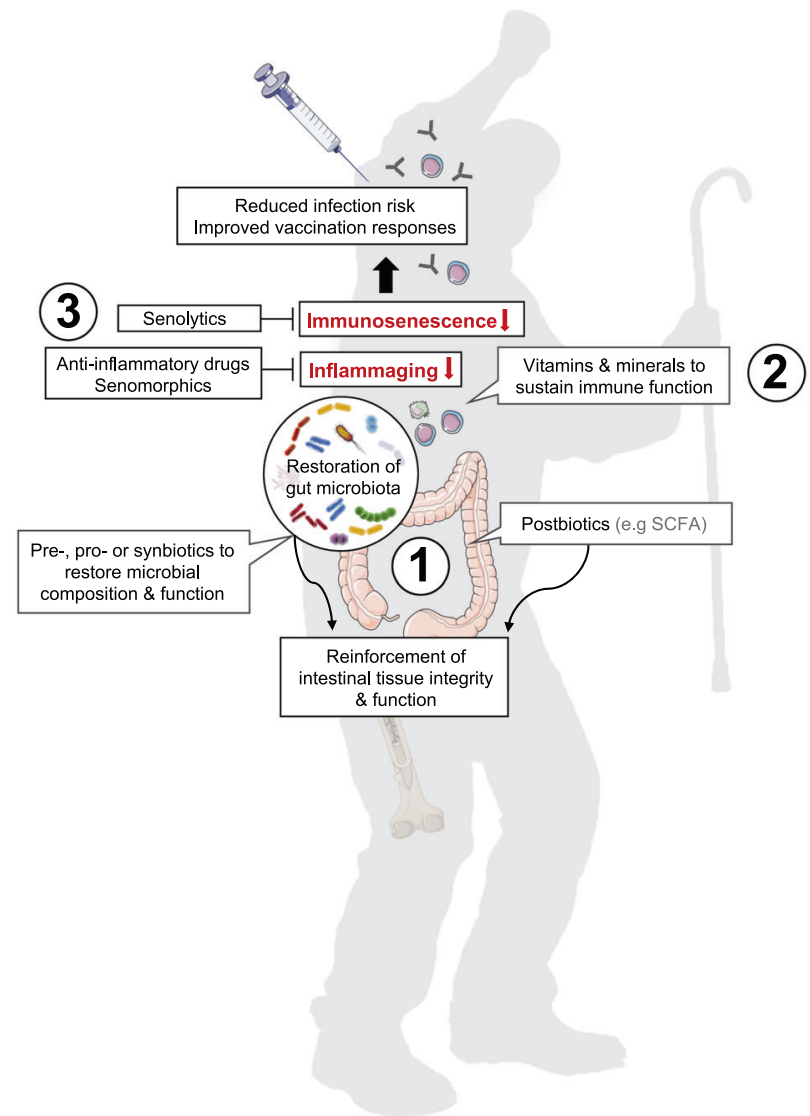

Fig. 2 Approaches to restore gut-microbial homeostasis, reduce inflammaging, and immunosenescence to support immunity in the elderly. Nutritional intervention with pre- pro- or synbiotics as well as metabolites thereof (e.g., SCFAs) may help to restore age-related declines in gut-microbial composition and function, reinforce intestinal integrity and reduce systemic low-grade inflammation (1). Supplementation with vitamins and minerals contributes to normal immune cell functioning (2). Anti-inflammatory drugs or senomorphics may help to reduce inflammaging while senolytics directly eliminate senescent cells that fuel inflammaging (3). These approaches, as stand alone or in combination may help to reinforce host immunity to better control infections and mount appropriate vaccination responses as we age.

immunosenescence-common accomplices of immunemediated chronic disorders and frailty-are potentially targetable to sustain immunity and health as we age. While anti-inflammatory drugs and senotherapeutic approaches to selectively eliminate senescent cells (senolytics) or to suppress the senescence associated secretory phenotype (senomorphics) are quickly moving towards clinical trials as antiaging therapies [122-125] (Fig. 2), their long-term use needs to be carefully balanced with regard to susceptibility to infectious disease and potential other side effects. Further research is also needed to explain the paradox why reducing systemic low-grade inflammation may boost vaccine responses while the prevailing view in vaccinology is that adjuvants improve vaccine responses by promoting local inflammation [126]. 
Given the ever-growing impact of the gut microbiome on the host-immune system, it is reasonable to speculate that restoring age-related declines in gut-microbial richness and function-be it through personalized nutrition or supplements-may represent a prophylactic measure to fight functional declines in immune fitness. In this context, pre-, pro-, and postbiotics or synbiotics with the ability to reinforce immunity through supporting intestinal barrier integrity or by regulating inflammatory processes have been tested in clinical settings (Table 1). However, a lack of consistency between studies, strain specific differences or doses, prebiotic nature and quantity or age and medical conditions of the subjects have made it difficult to validate the effectiveness of such approaches to reinforce ageassociated declines in host-immune fitness. None the less, mining the gut microbiome is a treasure trove waiting to be unlocked, and gerontology is no exception here. As exemplified by numerous preclinical studies, restoration of a youthful microbiome has rejuvenating potential for the aged host through sustaining immunity and health-span [67, 69, 74]. Thus, a better understanding of the dynamic age-related changes in gut-microbial community structures and associated metabolome, how such alterations affect cellular immune networks and how these pathways can be therapeutically targeted will have wide-reaching implications for future strategies to reinforce or even rejuvenate the aging immune system. With a growing aging population, such solutions are urgently needed to support healthy aging and to slow down the ever-rising health care costs.

Acknowledgements We thank members of the Immunology and Cell Biology Labs at Nestlé Research for critical discussions and reading of this work.

\section{Compliance with ethical standards}

Conflict of interest BN and NM are employees of Société des Produits Nestlé S.A.

Publisher's note Springer Nature remains neutral with regard to jurisdictional claims in published maps and institutional affiliations.

\section{References}

1. Nikolich-Žugich J. The twilight of immunity: emerging concepts in aging of the immune system. Nat Immunol. 2018;19:10-9.

2. Crooke SN, Ovsyannikova IG, Poland GA, Kennedy RB. Immunosenescence and human vaccine immune responses. Immun Ageing. 2019;16:25-16.

3. Hägg $\mathrm{S}$, Jylhävä J, Wang $\mathrm{Y}, \mathrm{Xu} \mathrm{H}$, Metzner C, Annetorp M, et al. Age, frailty, and comorbidity as prognostic factors for short-term outcomes in patients with coronavirus disease 2019 in geriatric care. J Am Med Dir Assoc. 2020;21:1555-9.e2.

4. Tehrani S, Killander A, Åstrand P, Jakobsson J, Gille-Johnson P. Risk factors for death in adult COVID-19 patients: frailty predicts fatal outcome in older patients. Int $\mathrm{J}$ Infect Dis. 2021;102:415-21.

5. Badal VD, Vaccariello ED, Murray ER, Yu KE, Knight R, Jeste $\mathrm{DV}$, et al. The gut microbiome, aging, and longevity: a systematic review. Nutrients. 2020;12:3759.

6. Gensollen T, Iyer SS, Kasper DL, Blumberg RS. How colonization by microbiota in early life shapes the immune system. Science. 2016;352:539-44.

7. Belkaid Y, Hand TW. Role of the microbiota in immunity and inflammation. Cell. 2014;157:121-41.

8. Hooper LV, Macpherson AJ. Immune adaptations that maintain homeostasis with the intestinal microbiota. Nat Rev Immunol. 2010;10:159-69.

9. Khan SS, Singer BD, Vaughan DE. Molecular and physiological manifestations and measurement of aging in humans. Aging Cell. 2017;16:624-33.

10. Rattan SIS. Theories of biological aging: genes, proteins, and free radicals. Free Radic Res. 2006;40:1230-8.

11. Ferrucci L, Gonzalez-Freire M, Fabbri E, Simonsick E, Tanaka $\mathrm{T}$, Moore $\mathrm{Z}$, et al. Measuring biological aging in humans: a quest. Aging Cell. 2020;19:e13080.

12. Montecino-Rodriguez E, Berent-Maoz B, Dorshkind K. Causes, consequences, and reversal of immune system aging. J Clin Investig. 2013;123:958-65.

13. Calder PC, Bosco N, Bourdet-Sicard R, Capuron L, Delzenne N, Doré $\mathrm{J}$, et al. Health relevance of the modification of low grade inflammation in ageing (inflammageing) and the role of nutrition. Ageing Res Rev. 2017;40:95-119.

14. Sadighi Akha AA. Aging and the immune system: an overview. J Immunol Methods. 2018;463:21-6.

15. Agarwal S, Busse PJ. Innate and adaptive immunosenescence. Ann Allergy Asthma Immunol. 2010;104:183-90.

16. Solana R, Tarazona R, Gayoso I, Lesur O, Dupuis G, Fulop T. Innate immunosenescence: effect of aging on cells and receptors of the innate immune system in humans. Semin Immunol. 2012;24:331-41.

17. Elias HK, Bryder D, Park CY. Molecular mechanisms underlying lineage bias in aging hematopoiesis. Semin Hematol. 2017;54:4-11.

18. Goronzy JJ, Weyand CM. Understanding immunosenescence to improve responses to vaccines. Nat Immunol. 2013;14:428-36.

19. Thomas R, Wang W, Su D-M. Contributions of age-related thymic involution to immunosenescence and inflammaging. Immun Ageing. 2020;17:2-17.

20. Cianci R, Franza L, Massaro MG, Borriello R, De Vito F, Gambassi G. The interplay between immunosenescence and microbiota in the efficacy of vaccines. Vaccines. 2020;8:636.

21. Amsterdam D, Ostrov BE. The impact of the microbiome on immunosenescence. Immunol Investig. 2018;47:801-11.

22. Thoo L, Noti M, Krebs P. Keep calm: the intestinal barrier at the interface of peace and war. Cell Death Dis. 2019;10:849-13.

23. Franceschi C, Garagnani P, Parini P, Giuliani C, Santoro A. Inflammaging: a new immune-metabolic viewpoint for agerelated diseases. Nat Rev Endocrinol. 2018;14:576-90.

24. Franceschi C, Campisi J. Chronic inflammation (inflammaging) and its potential contribution to age-associated diseases. J Gerontol A Biol Sci Med Sci. 2014;69 Suppl 1:S4-9.

25. Giovannini S, Onder G, Liperoti R, Russo A, Carter C, Capoluongo $\mathrm{E}$, et al. Interleukin-6, C-reactive protein, and tumor necrosis factor-alpha as predictors of mortality in frail, community-living elderly individuals. J Am Geriatr Soc. 2011;59:1679-85.

26. Furman D, Campisi J, Verdin E, Carrera-Bastos P, Targ S, Franceschi C, et al. Chronic inflammation in the etiology of disease across the life span. Nat Med. 2019;25:1822-32. 
27. Chambers ES, Akbar AN. Can blocking inflammation enhance immunity during aging? J Allergy Clin Immunol. 2020;145:1323-31.

28. Prattichizzo F, Bonafè M, Olivieri F, Franceschi C. Senescence associated macrophages and "macroph-aging": are they pieces of the same puzzle? Aging. 2016;8:3159-60.

29. Franceschi C, Garagnani P, Vitale G, Capri M, Salvioli S. Inflammaging and 'Garb-aging'. Trends Endocrinol Metab. 2017;28:199-212.

30. Sanada F, Taniyama Y, Muratsu J, Otsu R, Shimizu H, Rakugi $\mathrm{H}$, et al. Source of chronic inflammation in aging. Front Cardiovasc Med Front. 2018;5:12.

31. Alter G, Sekaly RP. Beyond adjuvants: antagonizing inflammation to enhance vaccine immunity. Vaccine. 2015;33 Suppl 2: B55-9.

32. Tsang JS, Dobaño C, VanDamme P, Moncunill G, Marchant A, Othman RB, et al. Improving vaccine-induced immunity: can baseline predict outcome? Trends Immunol. 2020;41:457-65.

33. Parmigiani A, Alcaide ML, Freguja R, Pallikkuth S, Frasca D, Fischl MA, et al. Impaired antibody response to influenza vaccine in HIV-infected and uninfected aging women is associated with immune activation and inflammation. PLoS ONE. 2013;8: e79816.

34. Bartholomeus E, De Neuter N, Meysman P, Suls A, Keersmaekers N, Elias G, et al. Transcriptome profiling in blood before and after hepatitis B vaccination shows significant differences in gene expression between responders and nonresponders. Vaccine. 2018;36:6282-9.

35. Hung IFN, Zhang AJ, To KKW, Chan JFW, Li C, Zhu H-S, et al. Immunogenicity of intradermal trivalent influenza vaccine with topical imiquimod: a double blind randomized controlled trial. Clin Infect Dis. 2014;59:1246-55.

36. Pettersen FO, Torheim EA, Dahm AEA, Aaberge IS, Lind A, Holm M, et al. An exploratory trial of cyclooxygenase type 2 inhibitor in HIV-1 infection: downregulated immune activation and improved $\mathrm{T}$ cell-dependent vaccine responses. J Virol Am Soc Microbiol J. 2011;85:6557-66.

37. Baghaki S, Yalcin CE, Baghaki HS, Aydin SY, Daghan B, Yavuz E. COX2 inhibition in the treatment of COVID-19: review of literature to propose repositioning of celecoxib for randomized controlled studies. Int J Infect Dis. 2020;101:29-32.

38. Goldberg EL, Dixit VD. Drivers of age-related inflammation and strategies for healthspan extension. Immunol Rev. 2015;265:63-74.

39. Sciorati C, Gamberale R, Monno A, Citterio L, Lanzani C, De Lorenzo R, et al. Pharmacological blockade of TNF $\alpha$ prevents sarcopenia and prolongs survival in aging mice. Aging. 2020;12:23497-508.

40. Brigger D, Riether C, van Brummelen R, Mosher KI, Shiu A, Ding Z, et al. Eosinophils regulate adipose tissue inflammation and sustain physical and immunological fitness in old age. Nat Metab. 2020;2:688-702.

41. Ridker PM, MacFadyen JG, Everett BM, Libby P, Thuren T, Glynn RJ, et al. Relationship of C-reactive protein reduction to cardiovascular event reduction following treatment with canakinumab: a secondary analysis from the CANTOS randomised controlled trial. Lancet. 2018;391:319-28.

42. Ridker PM, Everett BM, Thuren T, MacFadyen JG, Chang WH, Ballantyne C, et al. Antiinflammatory therapy with canakinumab for atherosclerotic disease. N Engl J Med. 2017;377:1119-31.

43. Ridker PM, MacFadyen JG, Thuren T, Everett BM, Libby P, Glynn RJ, et al. Effect of interleukin-1 $\beta$ inhibition with canakinumab on incident lung cancer in patients with atherosclerosis: exploratory results from a randomised, double-blind, placebocontrolled trial. Lancet. 2017;390:1833-42.

44. Alpert A, Pickman Y, Leipold M, Rosenberg-Hasson Y, Ji X, Gaujoux R, et al. A clinically meaningful metric of immune age derived from high-dimensional longitudinal monitoring. Nat Med. 2019;25:487-95.

45. Krištić J, Vučković F, Menni C, Klarić L, Keser T, Beceheli I, et al. Glycans are a novel biomarker of chronological and biological ages. J Gerontol A Biol Sci Med Sci. 2014;69:779-89.

46. Ritchie SC, Würtz P, Nath AP, Abraham G, Havulinna AS, Fearnley LG, et al. The biomarker GlycA is associated with chronic inflammation and predicts long-term risk of severe infection. Cell Syst. 2015;1:293-301.

47. Chen R, Snyder M. Systems biology: personalized medicine for the future? Curr Opin Pharmacol. 2012;12:623-8.

48. O'Toole PW, Jeffery IB. Gut microbiota and aging. Sci Am Assoc Adv Sci. 2015;350:1214-5.

49. DeJong EN, Surette MG, Bowdish DME. The gut microbiota and unhealthy aging: disentangling cause from consequence. Cell Host Microbe. 2020;28:180-9.

50. Yatsunenko T, Rey FE, Manary MJ, Trehan I, Dominguez-Bello MG, Contreras M, et al. Human gut microbiome viewed across age and geography. Nature. 2012;486:222-7.

51. GBD 2017 Causes of Death Collaborators. Global, regional, and national age-sex-specific mortality for 282 causes of death in 195 countries and territories, 1980-2017: a systematic analysis for the Global Burden of Disease Study 2017. Lancet. 2018;392:1736-88.

52. Xu C, Zhu H, Qiu P. Aging progression of human gut microbiota. BMC Microbiol. 2019;19:236-10.

53. Jeffery IB, Lynch DB, O'Toole PW. Composition and temporal stability of the gut microbiota in older persons. ISME J. 2016;10:170-82.

54. Odamaki T, Kato K, Sugahara H, Hashikura N, Takahashi S, Xiao J-Z, et al. Age-related changes in gut microbiota composition from newborn to centenarian: a cross-sectional study. BMC Microbiol. 2016;16:90-12.

55. Biagi E, Candela M, Turroni S, Garagnani P, Franceschi C, Brigidi P. Ageing and gut microbes: perspectives for health maintenance and longevity. Pharmacol Res. 2013;69:11-20.

56. Biagi E, Nylund L, Candela M, Ostan R, Bucci L, Pini E, et al. Through ageing, and beyond: gut microbiota and inflammatory status in seniors and centenarians. PLoS ONE. 2010;5: e10667.

57. Nagpal R, Mainali R, Ahmadi S, Wang S, Singh R, Kavanagh K, et al. Gut microbiome and aging: Physiological and mechanistic insights. Nutr Healthy Aging. 2018;4:267-85.

58. Buford TW. (Dis)Trust your gut: the gut microbiome in agerelated inflammation, health, and disease. Microbiome. 2017; 5:80-11.

59. Zmora N, Suez J, Elinav E. You are what you eat: diet, health and the gut microbiota. Nat Rev Gastroenterol Hepatol. 2019; 16:35-56.

60. Sonnenburg ED, Smits SA, Tikhonov M, Higginbottom SK, Wingreen NS, Sonnenburg JL. Diet-induced extinctions in the gut microbiota compound over generations. Nature. 2016; 529:212-5.

61. Mitchell EL, Davis AT, Brass K, Dendinger M, Barner R, Gharaibeh R, et al. Reduced intestinal motility, mucosal barrier function, and inflammation in aged monkeys. J Nutr Health Aging. 2017;21:354-61.

62. Funk MC, Zhou J, Boutros M. Ageing, metabolism and the intestine. EMBO Rep. 2020;21:e50047.

63. Soenen S, Rayner CK, Jones KL, Horowitz M. The ageing gastrointestinal tract. Curr Opin Clin Nutr Metab Care. 2016;19:12-8.

64. Pentinmikko N, Katajisto $P$. The role of stem cell niche in intestinal aging. Mech Ageing Dev. 2020;191:111330.

65. Moger-Reischer RZ, Lennon JT. Microbial ageing and longevity. Nat Rev Microbiol. 2019;17:679-90. 
66. Aleman FDD, Valenzano DR. Microbiome evolution during host aging. PLoS Pathog. 2019;15:e1007727.

67. Clark RI, Salazar A, Yamada R, Fitz-Gibbon S, Morselli M, Alcaraz J, et al. Distinct shifts in microbiota composition during drosophila aging impair intestinal function and drive mortality. Cell Rep. 2015;12:1656-67.

68. Guo L, Karpac J, Tran SL, Jasper H. PGRP-SC2 promotes gut immune homeostasis to limit commensal dysbiosis and extend lifespan. Cell. 2014;156:109-22.

69. Li H, Qi Y, Jasper H. Preventing age-related decline of gut compartmentalization limits microbiota dysbiosis and extends lifespan. Cell Host Microbe. 2016;19:240-53.

70. Smith P, Willemsen D, Popkes M, Metge F, Gandiwa E, Reichard M, et al. Regulation of life span by the gut microbiota in the short-lived African turquoise killifish. ELife. 2017;6: e1002352.

71. Bárcena C, Valdés-Mas R, Mayoral P, Garabaya C, Durand S, Rodríguez F, et al. Healthspan and lifespan extension by fecal microbiota transplantation into progeroid mice. Nat Med. 2019;25:1234-42.

72. Bodogai M, O'Connell J, Kim K, Kim Y, Moritoh K, Chen C, et al. Commensal bacteria contribute to insulin resistance in aging by activating innate B1a cells. Sci Transl Med. 2018;10: eaat 4271 .

73. Ansaldo E, Slayden LC, Ching KL, Koch MA, Wolf NK, Plichta DR, et al. Akkermansia muciniphila induces intestinal adaptive immune responses during homeostasis. Science. 2019; 364:1179-84.

74. Fransen F, van Beek AA, Borghuis T, Aidy SE, Hugenholtz F, van der Gaast-de JonghC, et al. Aged gut microbiota contributes to systemical inflammaging after transfer to germ-free mice. Front Immunol. 2017;8:1385.

75. Thevaranjan N, Puchta A, Schulz C, Naidoo A, Szamosi JC, Verschoor CP, et al. Age-associated microbial dysbiosis promotes intestinal permeability, systemic inflammation, and macrophage dysfunction. Cell Host Microbe. 2017;21: 455-66.e4.

76. Donaldson DS, Pollock J, Vohra P, Stevens MP, Mabbott NA. Microbial stimulation reverses the age-related decline in $\mathrm{M}$ cells in aged mice. iScience. 2020;23:101147.

77. Josefsdottir KS, Baldridge MT, Kadmon CS, King KY. Antibiotics impair murine hematopoiesis by depleting the intestinal microbiota. Blood. 2017;129:729-39.

78. Broxmeyer HE, Liu Y, Kapur R, Orschell CM, Aljoufi A, Ropa JP, et al. Fate of hematopoiesis during aging. what do we really know, and what are its implications? Stem Cell Rev Rep. 2020;16:1020-48

79. Kovtonyuk LV, Fritsch K, Feng X, Manz MG, Takizawa H. Inflamm-aging of hematopoiesis, hematopoietic stem cells, and the bone marrow microenvironment. Front Immunol Front. 2016;7:502.

80. Belkaid Y, Harrison OJ. Homeostatic immunity and the microbiota. Immunity. 2017;46:562-76.

81. Zheng D, Liwinski T, Elinav E. Interaction between microbiota and immunity in health and disease. Cell Res. 2020;30:492-506.

82. Rooks MG, Garrett WS. Gut microbiota, metabolites and host immunity. Nat Rev Immunol. 2016;16:341-52.

83. Valdez Y, Brown EM, Finlay BB. Influence of the microbiota on vaccine effectiveness. Trends Immunol. 2014;35:526-37.

84. Collins N, Belkaid Y. Do the microbiota influence vaccines and protective immunity to pathogens? engaging our endogenous adjuvants. Cold Spring Harb Perspect Biol. 2018;10:a028860.

85. Littman DR. Do the microbiota influence vaccines and protective immunity to pathogens? If so, is there potential for efficacious microbiota-based vaccines? Cold Spring Harb Perspect Biol. 2018;10:a029355.
86. Velasquez DE, Parashar U, Jiang B. Decreased performance of live attenuated, oral rotavirus vaccines in low-income settings: causes and contributing factors. Expert Rev Vaccines. 2018;17:145-61.

87. Woo PC, Tsoi HW, Wong LP, Leung HC, Yuen KY. Antibiotics modulate vaccine-induced humoral immune response. Clin Diagn Lab Immunol. 1999;6:832-7.

88. Lynn MA, Tumes DJ, Choo JM, Sribnaia A, Blake SJ, Leong LEX, et al. Early-life antibiotic-driven dysbiosis leads to dysregulated vaccine immune responses in mice. Cell Host Microbe. 2018;23:653-5.

89. Nakaya HI, Wrammert J, Lee EK, Racioppi L, Marie-Kunze S, Haining WN, et al. Systems biology of vaccination for seasonal influenza in humans. Nat Immunol. 2011;12:786-95.

90. Oh JZ, Ravindran R, Chassaing B, Carvalho FA, Maddur MS, Bower M, et al. TLR5-mediated sensing of gut microbiota is necessary for antibody responses to seasonal influenza vaccination. Immunity. 2014;41:478-92.

91. Kim D, Kim Y-G, Seo S-U, Kim D-J, Kamada N, Prescott D, et al. Nod2-mediated recognition of the microbiota is critical for mucosal adjuvant activity of cholera toxin. Nat Med. 2016; 22:524-30.

92. Akatsu H, Nagafuchi S, Kurihara R, Okuda K, Kanesaka T, Ogawa N, et al. Enhanced vaccination effect against influenza by prebiotics in elderly patients receiving enteral nutrition. Geriatr Gerontol Int. 2016;16:205-13.

93. Bunout D, Barrera G, Hirsch S, Gattas V, la Maza de MP, Haschke F, et al. Effects of a nutritional supplement on the immune response and cytokine production in free-living Chilean elderly. JPEN J Parenter Enter Nutr. 2004;28:348-54.

94. Langkamp-Henken B, Bender BS, Gardner EM, HerrlingerGarcia KA, Kelley MJ, Murasko DM, et al. Nutritional formula enhanced immune function and reduced days of symptoms of upper respiratory tract infection in seniors. J Am Geriatr Soc. 2004;52:3-12.

95. Langkamp-Henken B, Wood SM, Herlinger-Garcia KA, Thomas DJ, Stechmiller JK, Bender BS, et al. Nutritional formula improved immune profiles of seniors living in nursing homes. $\mathbf{J}$ Am Geriatr Soc. 2006;54:1861-70.

96. Lewis S, Burmeister S, Brazier J. Effect of the prebiotic oligofructose on relapse of Clostridium difficile-associated diarrhea: a randomized, controlled study. Clin Gastroenterol Hepatol. 2005;3:442-8.

97. Maeda H, Ichihashi K, Fujii T, Omura K, Zhu X, Anazawa M, et al. Oral administration of hydrolyzed rice bran prevents the common cold syndrome in the elderly based on its immunomodulatory action. Biofactors. 2004;21:185-7.

98. Rayes N, Hansen S, Seehofer D, Müller AR, Serke S, Bengmark $\mathrm{S}$, et al. Early enteral supply of fiber and Lactobacilli versus conventional nutrition: a controlled trial in patients with major abdominal surgery. Nutrition. 2002;18:609-15.

99. Shimoni Z, Averbuch Y, Shir E, Gottshalk T, Kfir D, Niven M, et al. The addition of fiber and the use of continuous infusion decrease the incidence of diarrhea in elderly tube-fed patients in medical wards of a general regional hospital: a controlled clinical trial. J Clin Gastroenterol. 2007;41:901-5.

100. Spapen H, Diltoer M, Van Malderen C, Opdenacker G, Suys E, Huyghens L. Soluble fiber reduces the incidence of diarrhea in septic patients receiving total enteral nutrition: a prospective, double-blind, randomized, and controlled trial. Clin Nutr. 2001;20:301-5.

101. Koh A, De Vadder F, Kovatcheva-Datchary P, Bäckhed F. From dietary fiber to host physiology: short-chain fatty acids as key bacterial metabolites. Cell. 2016;165:1332-45.

102. Arpaia N, Campbell C, Fan X, Dikiy S, van der Veeken J, deRoos P, et al. Metabolites produced by commensal bacteria 
promote peripheral regulatory T-cell generation. Nature. 2013; 504:451-5.

103. Marchesi JR, Adams DH, Fava F, Hermes GDA, Hirschfield GM, Hold G, et al. The gut microbiota and host health: a new clinical frontier. Gut. 2016;65:330-9.

104. Ríos-Covián D, Ruas-Madiedo P, Margolles A, Gueimonde M, de Los Reyes-Gavilán CG, Salazar N. Intestinal short chain fatty acids and their link with diet and human health. Front Microbiol. 2016;7:185.

105. Camous X, Visan L, Ying CTT, Abel B, Nyunt MSZ, Narang V, et al. Healthy elderly Singaporeans show no age-related humoral hyporesponsiveness nor diminished plasmablast generation in response to influenza vaccine. Immun Ageing. 2018;15:28-6.

106. Narang V, Lu Y, Tan C, Camous XFN, Nyunt SZ, Carre C, et al. Influenza vaccine-induced antibody responses are not impaired by frailty in the community-dwelling elderly with natural influenza exposure. Front Immunol. 2018;9:2465.

107. Bauer JM, De Castro A, Bosco N, Romagny C, Diekmann R, Benyacoub J, et al. Influenza vaccine response in communitydwelling German prefrail and frail individuals. Immun Ageing. 2017;14:17-0.

108. Hur Y-G, Gorak-Stolinska P, Lalor MK, Mvula H, Floyd S, Raynes $\mathbf{J}$, et al. Factors affecting immunogenicity of BCG in infants, a study in Malawi, The Gambia and the UK. BMC Infect Dis. 2014;14:184-10.

109. Huda MN, Lewis Z, Kalanetra KM, Rashid M, Ahmad SM, Raqib R, et al. Stool microbiota and vaccine responses of infants. Pediatrics. 2014;134:e362-72.

110. Lagos R, Fasano A, Wasserman SS, Prado V, San Martin O, Abrego P, et al. Effect of small bowel bacterial overgrowth on the immunogenicity of single-dose live oral cholera vaccine CVD 103-HgR. J Infect Dis. 1999;180:1709-12.

111. Kollmann TR, Levy O, Montgomery RR, Goriely S. Innate immune function by Toll-like receptors: distinct responses in newborns and the elderly. Immunity. 2012;37:771-83.

112. Smolen KK, Ruck CE, Fortuno ES, Ho K, Dimitriu P, Mohn WW, et al. Pattern recognition receptor-mediated cytokine response in infants across 4 continents. J Allergy Clin Immunol. 2014;133:818-26.e4.

113. Grassly NC, Praharaj I, Babji S, Kaliappan SP, Giri S, Venugopal S, et al. The effect of azithromycin on the immunogenicity of oral poliovirus vaccine: a double-blind randomised placebocontrolled trial in seronegative Indian infants. Lancet Infect Dis. 2016;16:905-14.

114. Harris VC, Haak BW, Handley SA, Jiang B, Velasquez DE, Hykes BL, et al. Effect of antibiotic-mediated microbiome modulation on rotavirus vaccine immunogenicity: a human, randomized-control proof-of-concept trial. Cell Host Microbe. 2018;24:197-207.e4.

115. Hagan T, Cortese M, Rouphael N, Boudreau C, Linde C, Maddur MS, et al. Antibiotics-driven gut microbiome perturbation alters immunity to vaccines in humans. Cell 2019; 178:1313-3.

116. Macpherson AJ. Do the microbiota influence vaccines and protective immunity to pathogens? Issues of sovereignty, federalism, and points-testing in the prokaryotic and eukaryotic spaces of the host-microbial superorganism. Cold Spring Harb Perspect Biol. 2018;10:a029363.

117. Arai S. Functional food science in Japan: state of the art. Biofactors. 2000;12:13-6.

118. Besselink MG, van Santvoort HC, Buskens E, Boermeester MA, van Goor H, Timmerman HM, et al. Probiotic prophylaxis in predicted severe acute pancreatitis: a randomised, double-blind, placebo-controlled trial. Lancet. 2008;371:651-9.

119. Hickson M, D'Souza AL, Muthu N, Rogers TR, Want S, Rajkumar $\mathrm{C}$, et al. Use of probiotic Lactobacillus preparation to prevent diarrhoea associated with antibiotics: randomised double blind placebo controlled trial. BMJ. 2007;335:80.

120. Alberda C, Marcushamer S, Hewer T, Journault N, Kutsogiannis D. Feasibility of a lactobacillus casei drink in the intensive care unit for prevention of antibiotic associated diarrhea and clostridium difficile. Nutrients. 2018;10:539.

121. Butler CC, Lau M, Gillespie D, Owen-Jones E, Lown M, Wootton M, et al. Effect of probiotic use on antibiotic administration among care home residents: a randomized clinical trial. Jama. 2020;324:47-56.

122. Kirkland JL, Tchkonia T. Senolytic drugs: from discovery to translation. J Intern Med. 2020;288:518-36.

123. Hickson LJ, Langhi Prata LGP, Bobart SA, Evans TK, Giorgadze N, Hashmi SK, et al. Senolytics decrease senescent cells in humans: preliminary report from a clinical trial of Dasatinib plus Quercetin in individuals with diabetic kidney disease. EBioMedicine. 2019;47:446-56.

124. Xu M, Pirtskhalava T, Farr JN, Weigand BM, Palmer AK, Weivoda MM, et al. Senolytics improve physical function and increase lifespan in old age. Nat Med. 2018;24:1246-56.

125. Niedernhofer LJ, Robbins PD. Senotherapeutics for healthy ageing. Nat Rev Drug Discov. 2018;17:377-7.

126. Pereira B, Xu X-N, Akbar AN. Targeting inflammation and immunosenescence to improve vaccine responses in the elderly. Front Immunol. 2020;11:583019.

127. Akatsu H, Arakawa K, Yamamoto T, Kanematsu T, Matsukawa N, Ohara $\mathrm{H}$, et al. Lactobacillus in jelly enhances the effect of influenza vaccination in elderly individuals. J Am Geriatr Soc. 2013;61:1828-30.

128. Akatsu H, Iwabuchi N, Xiao J-Z, Matsuyama Z, Kurihara R, Okuda $\mathrm{K}$, et al. Clinical effects of probiotic Bifidobacterium longum BB536 on immune function and intestinal microbiota in elderly patients receiving enteral tube feeding. JPEN J Parenter Enter Nutr. 2013;37:631-40.

129. Anderson ADG, McNaught CE, Jain PK, MacFie J. Randomised clinical trial of synbiotic therapy in elective surgical patients. Gut. 2004;53:241-5.

130. Boge T, Rémigy M, Vaudaine S, Tanguy J, Bourdet-Sicard R, van der Werf $\mathrm{S}$. A probiotic fermented dairy drink improves antibody response to influenza vaccination in the elderly in two randomised controlled trials. Vaccine. 2009;27:5677-84.

131. Bosch M, Méndez M, Pérez M, Farran A, Fuentes MC, Cuñé J. Lactobacillus plantarum CECT7315 and CECT7316 stimulate immunoglobulin production after influenza vaccination in elderly. Nutr Hosp. 2012;27:504-9.

132. Bunout D, Hirsch S, Pía de la Maza M, Muñoz C, Haschke F, Steenhout $\mathrm{P}$, et al. Effects of prebiotics on the immune response to vaccination in the elderly. JPEN J Parenter Enter Nutr. 2002;26:372-6.

133. Salomão MCC, Heluany-Filho MA, Menegueti MG, Kraker MEAD, Martinez R, Bellissimo-Rodrigues F. A randomized clinical trial on the effectiveness of a symbiotic product to decolonize patients harboring multidrug-resistant Gram-negative bacilli. Rev Soc Bras Med Trop. 2016;49:559-66.

134. Eggers S, Barker AK, Valentine S, Hess T, Duster M, Safdar N. Effect of Lactobacillus rhamnosus HN001 on carriage of Staphylococcus aureus: results of the impact of probiotics for reducing infections in veterans (IMPROVE) study. BMC Infect Dis. 2018;18:129-8.

135. Enani S, Przemska-Kosicka A, Childs CE, Maidens C, Dong H, Conterno $\mathrm{L}$, et al. Impact of ageing and a synbiotic on the immune response to seasonal influenza vaccination; a randomised controlled trial. Clin Nutr. 2018;37:443-51.

136. Fonollá J, Gracián C, Maldonado-Lobón JA, Romero C, Bédmar A, Carrillo JC, et al. Effects of Lactobacillus coryniformis K8 CECT5711 on the immune response to influenza vaccination and 
the assessment of common respiratory symptoms in elderly subjects: a randomized controlled trial. Eur J Nutr. 2019; 58:83-90.

137. Fukushima Y, Miyaguchi S, Yamano T, Kaburagi T, Iino H, Ushida $\mathrm{K}$, et al. Improvement of nutritional status and incidence of infection in hospitalised, enterally fed elderly by feeding of fermented milk containing probiotic Lactobacillus johnsonii La1 (NCC533). Br J Nutr. 2007;98:969-77.

138. Jain PK, McNaught CE, Anderson ADG, MacFie J, Mitchell CJ. Influence of synbiotic containing Lactobacillus acidophilus La5, Bifidobacterium lactis Bb 12, Streptococcus thermophilus, Lactobacillus bulgaricus and oligofructose on gut barrier function and sepsis in critically ill patients: a randomised controlled trial. Clin Nutr. 2004;23:467-75.

139. Maruyama M, Abe R, Shimono T, Iwabuchi N, Abe F, Xiao J-Z. The effects of non-viable Lactobacillus on immune function in the elderly: a randomised, double-blind, placebo-controlled study. Int J Food Sci Nutr. 2016;67:67-73.

140. Namba K, Hatano M, Yaeshima T, Takase M, Suzuki K. Effects of Bifidobacterium longum BB536 administration on influenza infection, influenza vaccine antibody titer, and cell-mediated immunity in the elderly. Biosci Biotechnol Biochem. 2010; 74:939-45.

141. Przemska-Kosicka A, Childs CE, Enani S, Maidens C, Dong H, Dayel IB, et al. Effect of a synbiotic on the response to seasonal influenza vaccination is strongly influenced by degree of immunosenescence. Immun Ageing. 2016;13:6-12.

142. Russolillo N, Ferrero A, Vigano L, Langella S, Briozzo A, Ferlini M, et al. Impact of perioperative symbiotic therapy on infectious morbidity after Hpb Surgery in jaundiced patients: a randomized controlled trial. Updates Surg. 2014;66:203-10.

143. Van Puyenbroeck K, Hens N, Coenen S, Michiels B, Beunckens C, Molenberghs G, et al. Efficacy of daily intake of Lactobacillus casei Shirota on respiratory symptoms and influenza vaccination immune response: a randomized, double-blind, placebocontrolled trial in healthy elderly nursing home residents. Am J Clin Nutr. 2012;95:1165-71.

144. Yamamoto Y, Saruta J, Takahashi T, To M, Shimizu T, Hayashi $\mathrm{T}$, et al. Effect of ingesting yogurt fermented with Lactobacillus delbrueckii ssp. bulgaricus OLL1073R-1 on influenza virus-bound salivary $\operatorname{IgA}$ in elderly residents of nursing homes: a randomized controlled trial. Acta Odontol Scand. 2019;77:517-24. 